Surv. Dig. Dis. 1983;1:I-IV

\title{
Contents, Vol. 1, 1983
}

No. 1 Editorial: A Prospectus 1

Gastrointestinal Carcinoids: An Update

Kessinger, A 2

Cancer in Inflammatory Bowel Disease

Greenstein, A.J.; Sachar, D.B 8

Collagenous Colitis: A Clinicopathological Review

Bogomoletz, W.V 19

Diagnosis of Pancreatitis

Kayasseh, L.; Gyr, K 26

Hepatic Drug Metabolism: Important Considerations for the Clinician

Knodell, R.G 34

Endoscopic Laser Therapy for Upper Gastrointestinal Tract Disease

Fleischer, D 42

Recognition and Treatment of Antibiotic-Associated Colitis

Bartlett, J.G 54

Drug Treatment of Duodenal Ulcer

Piper, D.W.; Middleton, W.R.J.; Kellow, J.E 64

No. 2 Nonsurgical Management of Selected Esophageal Disorders

Rozen, $\mathrm{P}$

69

Idiopathic Gastric Stasis

Ricci, D.A.; McCallum, R.W 79

Jejunoileal Bypass-Induced Liver Disease

Vanderhoof, J.A.; Tuma, D.J.; Antonson, D.L 97

The Clinical Entity of Idiopathic Portal Hypertension: A Review of 17 Cases

Takeshige, K.; Yamamoto, S 107

Duodenoscopic Transpapillary Techniques and Results in Biliary and Pancreatic Diseases:

An Update

Goldenberg, D.A 114

Psychosocial Aspects of the Irritable Bowel Syndrome

Drossman, D.A 130

Arthritis Accompanying Inflammatory Bowel Disease

Worth, D.A 136

Contents

3 Cholestatic Disorders of the Infant

Suchy, F.J.; Balistreri, W.F 141

Motility Disorders of the Lower Esophagus

Blackwell, J.N.; Castell, D.0 157

The Management of Patients with Gastrinoma

Sener, S.F.; Brennan, M.F 169 
Travelers' Diarrhea, New Perspectives

Johnson, P.C.; Ericsson, CD.; DuPont, H.L 179

Immunological Mechanisms of Chronic Ulcerative Colitis

Marbet, U.A 190

Our Experiences with Vitamin Malabsorption: An Overview

Baker, FL; Frank, 0203

$4 \quad$ Intestinal Blood Flow: Relations to Function

Granger, D.N.; Kvietys, P.R.; Parks, D.A.; Benoit, J.N 217

Barrett's Esophagus

Bonnice, C.A.; Eastwood, G.L 229

Current Status of Gastric Reduction for Obesity

Mason, E.E 243

The Features of Early Gastric Carcinoma

Nakazawa, S.; Kozawa, H 253

Can Early Gastric Cancer Be Easily Diagnosed outside Japan?

Peura, D.A 261

Peutz-Jeghers Syndrome

Rasenack, U 264

Treatment of Rectal Haemorrhoids: The Old and the New

Keighley, M.R.B 271

Author Index 281

Subject Index 282 